\title{
Environmental Variation and Cohort Effects in an Antarctic Predator
}

\author{
Robert A. Garrott, Jay J. Rotella, Donald B. Siniff, Claire L. Parkinson, and Glenn E. \\ Stauffer
}

R. A. Garrott, Dept of Ecology, Montana State Univ., 310 Lewis Hall, Bozeman, MT 59717, USA, fax 406-994-3190,rgarrott@montana.edu

J. J. Rotella, Dept of Ecology, Montana State Univ., 310 Lewis Hall, Bozeman, MT 59717, USA, fax 406-994-3190, rotella@montana.edu

D. B. Siniff, Dept of Ecology, Evolution and Behavioral Biology, Univ. of Minnesota, 100 Ecology Building, St Paul, MN 55108, USA, fax 612-624-6777, sinif001@umn.edu

C. L. Parkinson, Cryospheric Sciences Branch/Code 614.1, NASA Goddard Space Flight Center, Greenbelt, MD 20771, USA, fax 301-614-5644, claire.l.parkinson@nasa.gov

G. E. Stauffer, Dept of Ecology, Montana State Univ., 310 Lewis Hall, Bozeman, MT 59717, fax 406-994-3190, glenn.stauffer@msu.montana.edu 


\begin{abstract}
Understanding the potential influence of environmental variation experienced by animals during early stages of development on their subsequent demographic performance can contribute to our understanding of population processes and aid in predicting impacts of global climate change on ecosystem functioning. Using data from 4,178 tagged female Weddell seal pups born into 20 different cohorts, and 30 years of observations of the tagged seals, we evaluated the hypothesis that environmental conditions experienced by young seals, either indirectly through maternal effects and/or directly during the initial period of juvenile nutritional independence, have longterm effects on individual demographic performance. We documented an approximately 3-fold difference in the proportion of each cohort that returned to the pupping colonies and produced a pup within the first 10 years after birth. We found only weak evidence for a correlation between annual environmental conditions during the juvenile-independence period and cohort recruitment probability. Instead, the data strongly supported an association between cohort recruitment probability and the regional extent of sea ice experienced by the mother during the winter the pup was in utero. We suggest that inter-annual variation in winter sea-ice extent influences the foraging success of pregnant seals by moderating the regional abundance of competing predators that cannot occupy areas of consolidated sea ice, and by directly influencing the abundance of mid-trophic prey species that are sea-ice obligates. We hypothesize that this environmentallyinduced variation in maternal nutrition dictates the extent of maternal energetic investment in offspring, resulting in cohort variation in mean size of pups at weaning which, in turn, contributes to an individual's phenotype and its ultimate fitness. These linkages between sea ice and trophic dynamics, combined with demonstrated and predicted changes in the duration and extent of sea ice associated with climate change, suggest significant alterations in Antarctic marine ecosystems in the future.
\end{abstract}




\section{Introduction}

2 In most ecological contexts the environments in which animal populations exist are inherently

3 variable. Ecological studies of the impacts of environmental variation on animal population

4 processes has a long and rich history and have demonstrated the direct and immediate influences

5 of environmental variability on basic demographic processes (Turchin 2003). A more recent

6 area of investigation is the influence of nutritional or developmental programming on the

7 demographic performance of individuals subjected to differing environmental conditions during

8 the early stages of life. Studies across a wide range of taxa are revealing that this phenomenon

9 can result in cohorts produced during poor environmental conditions suffering reduced fitness, as

10 indexed by survival, fecundity, or recruitment rates, compared to cohorts born under more

11 favorable conditions (Lindström 1999). Such cohort effects have important consequences for

12 understanding features of population dynamics such as variability, stability, and delayed density

13 dependence (Beckerman et al. 2003, Lindström and Kokko 2002).

14 The study of cohort effects in long-lived, large-bodied mammals is particularly

15 interesting because these animals have a prolonged developmental period that often extends for

16 several years before adult body size and sexual maturity are attained. The developmental period

17 for such animals can be partitioned into the maternal-dependency phase, which includes the

18 intrauterine period from conception to birth and the subsequent period of maternal provisioning

19 through lactation and nursing. The juvenile phase begins when an animal is weaned, thus

20 becoming nutritionally independent, and continues until the animal attains maturity. Because

21 development extends over multiple seasons and years, environmental conditions influencing an

22 individual can vary considerably from one developmental period to the next, providing an 
23 opportunity to evaluate the relative contribution of environmental conditions during various

24 stages of development to any realized cohort effect.

25 Investigations of cohort effects in large mammals have been dominated by ungulate

26 studies in temperate and high latitudes (e.g., Albon et al. 1987, Festa-Bianchet et al. 1998,

27 Forchhammer et al. 2001). Ungulates generally accrue body reserves during the growing season

28 of one year, breed in autumn at maximal body mass, and nourish the fetus through the winter

29 period of energy restriction, primarily from body reserves. Birth occurs the following spring at

30 the onset of the next growing season when mothers are at minimal body mass (Anderson et al.

31 1974, Parker et al. 1993). Mothers then feed on nutritious forages during the lactation period and

32 gradually wean young near the end of the growing season. Using the capital-income typology

33 for describing reproductive investment (Jönsson 1997) and standardizing its application to the

34 entire reproductive cycle (Stephens et al. 2009), ungulate reproduction thus represents a blend of

35 capital investment during the intrauterine period and income investment during the post-partum

36 maternal provisioning period. A consequence of this capital-income sequence of energetic

37 investment in ungulates is that the environmental conditions influencing the development of a

38 cohort of young ungulates during the maternal dependency period span two growing seasons as

39 well as a winter season, with the environmental conditions during the second growing season

40 contributing to both the maternal dependency period and the initial period of juvenile

41 independence.

42 Demographic studies of marine mammals, particularly of large phocids, provide

43 opportunities to expand our understanding of cohort effects to a taxon that represent secondary

44 consumers. These mammals have a considerably different pattern of energetic investment in

45 reproduction from ungulates that enhances our ability to assess the relative contribution of 
environmental variability experienced during the maternal-dependence and juvenile phase to any

47 realized cohort effect (Shultz and Bowen 2004). One of the largest phocids is the Weddell seal

48 (Leptonychotes weddellii), which is associated with the fast ice around the coast of Antarctica

49 and attains a body size of 500-580 kg (Wheatley et al. 2006, Proffitt et al. 2007a). Weddell seals

50 fast during lactation (mid-October through early December) and breed at the end of the period of

51 lactation, hence placing them at a seasonal low point in body reserves at the start of the

52 reproductive cycle. Implantation is delayed until mid-January to mid-February followed by a

53 prolonged gestation period with energetic intake supporting both fetal development and

54 replenishment of body reserves. Birth occurs from mid-October through November, when

55 female body mass is at its maxima at the end of the seasonal cycle, after which body reserves are

56 rapidly transferred to the developing young during the post-partum maternal provisioning period

57 (Stirling 1969). Thus, reproduction depends on income investment during the intrauterine period

58 and capital investment during the post-partum maternal dependency period. Recent energetic

59 studies in Weddell seals confirm that feeding during the nursing period contributes nominal

60 resources to support lactation (Wheatley et al. 2008). Thus the reliance on body reserves during

61 the maternal provisioning period provides an unambiguous demarcation between environmental

62 conditions that influence the maternal dependency period experienced during a single summer-

63 winter annual cycle and those experienced by newly independent juveniles during the subsequent

64 annual cycle.

65 Here, we use 30 years of data from a long-term demographic study of Weddell seals

66 occupying Erebus Bay in the southern Ross Sea to test the hypothesis that environmental

67 conditions experienced by young seals during early development, either indirectly through

68 maternal effects and/or directly during the initial period of juvenile nutritional independence, 
69 have long-term effects on individual demographic performance. The objectives of this

70 investigation included (1) characterizing variability in the probability of recruitment of cohorts of

71 females born over periods with a wide range of environmental conditions, and (2) evaluating and

72 contrasting the strength of correlations among indices of environmental conditions that were

73 hypothesized to contribute to resources available during the maternal dependency and juvenile

74 development periods. The Erebus Bay Weddell seals represent the world's southernmost

75 breeding mammal population, with life history traits likely linked to marine conditions that

76 demonstrate substantial variability over multiple times scales (Cavalieri and Parkinson 2008,

77 Massom and Stammerjohn 2010). These attributes, combined with the long-term study of highly

78 detectable, known-age, individually marked seals (Hadley et al. 2007a, Rotella et al. 2009),

79 enhance the ability to detect and understand the potential influence of environmental variation

80 experienced during early stages of life on demographic performance.

81 High latitude systems are thought to be particularly sensitive to climate change (Croxall

82 et al. 2002, Parkinson 2004), and thus studies of the linkages between environmental conditions

83 and demographic processes in Antarctic populations contribute to understanding the ecological

84 consequences of this global phenomenon. In this respect, the Ross Sea is of special interest, as it

85 is one of the most productive areas of the Southern Ocean (Arrigo and van Dijken 2004),

86 represents the most pristine marine environment remaining on the planet (Halpern et al. 2008),

87 and, in striking contrast to trends in the Antarctic Peninsula (Vaughan et al. 2001, 2003) and

88 Arctic regions (Parkinson and Cavalieri 2008, Walsh 2008), is experiencing an increase in sea

89 ice coverage (Cavalieri and Parkinson 2008) and a gradual lengthening of the sea-ice season

90 (Parkinson 2004).

91 


\section{Methods}

\section{Study area and population}

94 The Erebus Bay study area is located in McMurdo Sound, the southernmost embayment of the

95 Ross Sea, Antarctica $\left(77^{\circ} 37^{\prime} 12^{\prime \prime}\right.$ to $77^{\circ} 52^{\prime} 12^{\prime \prime}$ S, $166^{\circ} 18^{\prime}$ to $167^{\circ}$ E). Each austral spring, pupping

96 colonies form along perennial cracks in the sea ice created by tidal movement of the fast ice

97 against land or glacial ice. The fast ice associated with the pupping colonies is consistently

98 present during the spring reproduction period with annual variation primarily limited to the

99 thickness of the ice that, in turn, depends on annual variation in ice break out during the austral

100 summer. Pupping occurs on the ice surface from mid October through November, and mothers

101 remain in close association with their pups throughout the 30-45 day lactation period. Females

102 who have not yet had a pup (pre-breeders) and parous females that are skipping pupping also

103 haul out in the study area each year. Females come into estrous approximately 35 days after

104 parturition, and breeding occurs within underwater territories centered on the ice cracks at each

105 colony (Stirling 1969). Limited data from telemetry studies suggests that most seals move north

106 into the Ross Sea after the breeding season and remain there until returning to traditional

107 pupping colonies in spring. The estimated number of female seals in the breeding population

108 ranged from 438 to 623 and averaged 527 during 1982-2003 (Rotella et al. 2009). Typically,

109 300-600 pups are born per year at colonies in Erebus Bay, and females surviving to reproductive

110 age have strong natal philopatry (Cameron and Siniff 2004). Age at first reproduction for

111 females is variable and averages $7.6 \pm 1.7$ years (mean \pm SD; Hadley et al. 2006). Upon

112 recruiting to the breeding population, females typically produce a pup every 1.5-2.2 years,

113 depending on previous breeding experience and environmental conditions (Hadley et al. 2007a).

114 The oldest known animals in this population are 29 years old. 


\section{Data collection}

116 Each year from 1969 until the present, Weddell seal pups born within the Erebus Bay study area

117 have been individually marked (usually within several days of birth) with plastic livestock tags

118 attached to the interdigital webbing of each rear flipper. From 1969 to 1981, the proportion of

119 pups that were tagged varied, but since 1982 all pups in the study area have been tagged. In

120 addition, most seals with a broken or missing tag were retagged, and untagged adults were

121 tagged opportunistically upon sighting and capture. The majority of the tagging effort occurred

122 from approximately 15 October to 15 November each year, during the peak of parturition, when

123 colonies were visited every two to three days to tag newborn pups. Beginning in early

124 November of each year, six to eight resighting surveys were carried out throughout the study

125 area with surveys typically separated by three to five days and field work ending by mid-

126 December. Seals in this population could be readily approached within $0.5 \mathrm{~m}$, and thus,

127 observers were able to read tags on all marked animals that were observed.

128 Response variable (the proportion of female pups recuited by 10 years of age)

129 The response variable of interest was the proportion of females from a given birth cohort that

130 recruited to the breeding population by age 10 . The choice of age 10 represents the best

131 compromise that captures most recruitment while maximizing the number of cohorts that could

132 be included in the analysis, as Hadley et al. (2006) found that $93 \%$ of breeding females produce

133 their first offspring by age 10. Weddell seals have strong philopatry to their birth colony with

134 little evidence of permanent dispersal (Cameron and Siniff 2004), and the vast majority of all

135 young tagged in the Erebus Bay colonies are never detected after their birth year (Hadley et al.

136 2007b), thus it is likely that seals that have not recruited into the breeding population by age 10

137 died. The uninterrupted multi-decadal research effort using consistent tagging and resight 
138 methodology, combined with strong philopatry of female seals to their natal area (Cameron and

139 Siniff 2004) and nearly perfect detection probability of reproducing females (Hadley et al.

140 2006), provided high-quality encounter histories of females born in the Erebus Bay colonies for

141 developing the response variable. Using these individual encounter histories we developed a

142 dichotomous response variable by assigning a 0 or 1 to each tagged female pup in each cohort

143 based on whether she recruited by age 10 or not. Based on those 0's and 1's we thus obtained an

144 estimate of the proportion of females in each cohort that recruited. The numbers of pups

145 annually tagged prior to 1980 were considered too low to provide a representative sample of the

146 cohort, and 2009 was the most recent year for which resight data were available. Hence we

147 included 20 cohorts from 1980 through 1999 in the analysis.

148 Environmental covariates

149 We evaluated seasonal covariates at three spatial scales that indexed environmental variation we

150 suspected may influence primary production and other attributes of the marine system that result

151 in variation in prey availability, and the distribution and abundance of other predators that

152 compete for the same fish resources with Weddell seals. We considered these covariates for two

153 time periods to evaluate the relative importance of environmental conditions during the maternal 154 dependency period and the initial period of juvenile nutritional independence.

155 Southern Oscillation Index (SOI)

156 At the broadest scale there is strong evidence that the El Niño/Southern Oscillation (ENSO)

157 phenomenon in the tropical Pacific linearly covaries with Antarctic sea ice fields and that this

158 teleconnection is the most significant link with extra-polar climate variability (Yuan 2004; Yuan

159 and Li 2008). We used the Southern Oscillation Index (SOI), which describes the ENSO

160 atmosphere-ocean interactions in tropical and subtropical latitudes (Stenseth et al. 2003), and 
161 calculated a three month running average of the monthly SOI for summer (Dec-Feb, SOI $)$ and

162 winter (July-Sept, SOI ${ }_{\mathrm{w}}$ ) periods (http://www.bom.gov.au/climate/current/soihtm1.shtml). SOI

163 is negatively associated with atmospheric pressure and sea-surface temperatures and is positively

164 associated with the extent and concentration of sea ice (Yuan 2004). SOI generally is in phase

165 with pupping rates in the study population (Testa et al. 1991) and positively correlated with the

166 size of the population (Rotella et al. 2009) and seal body mass (Proffitt et al. 2007a). Thus, we

167 predicted that SOI would be positively related to measures of cohort demographic performance,

168 such as the probability of recruitment.

169 Antarctic Dipole (ADP)

170 A second climate mode index, the Antarctic Dipole (ADP), was also considered as it represents

171 the ENSO 'footprint' at the southern high latitudes, but has its own characteristics in space and 172 time and persists after tropical forcing has diminished (Yuan and Li 2008). Similar to SOI, we

173 calculated a three-month running average of the Antarctic Dipole for summer (Dec-Feb, $\mathrm{ADP}_{\mathrm{s}}$ )

174 and winter (July-Sept, $\mathrm{ADP}_{\mathrm{w}}$ ). ADP is a more recently developed climate mode and has not yet

175 been employed much in biological studies, but we expected probability of recruitment to have

176 the same relationship with ADP as with SOI.

\section{$177 \quad$ Sea ice extent (SIE)}

178 At the intermediate spatial scale of the Ross Sea sector, defined as that portion of the Southern

179 Ocean between $160^{\circ} \mathrm{E}$ and $130^{\circ} \mathrm{W}$, we considered measures of summer and winter sea-ice extent

180 (SIE) as estimated from passive microwave satellite images (DMSP SSM/I, NASA team

181 algorithm; ftp://sidads.colorado.edu/pub/DATASETS/seaice/polar-stereo/trends-

182 climatologies/ice-extent/nasateam/) (Cavalieri et al. 1991). Winter sea-ice extent (SIE $\left.{ }_{\mathrm{w}}\right)$ was

183 defined as the September average and summer sea-ice extent $\left(\mathrm{SIE}_{\mathrm{s}}\right)$ was defined as the February 
184 average; September and February are typically the months of maximum and minimum sea ice

185 coverage, respectively, both in the Ross Sea and in the Southern Ocean as a whole (Cavalieri and

186 Parkinson 2008). Extensive compacted sea ice during summer reduces the amount of open water

187 available for phytoplankton blooms and atmospheric contributions of $\mathrm{CO}_{2}$ to ocean waters

188 (Arrigo and van Dijken 2007). Reduced primary production would likely cascade up the food

189 chain, reducing the abundance of prey for apex predators like Weddell seals (Proffitt et al.

190 2007a,b) and resulting in a negative correlation between $\mathrm{SIE}_{\mathrm{s}}$ and probability of recruitment.

191 Alternatively, increased sea-ice extent in summer may decrease the abundance of birds and

192 whales in the ecosystem, competing predators that are not as well adapted to dense sea ice. This

193 would suggest a positive rather than negative correlation between $\mathrm{SIE}_{\mathrm{s}}$ and probability of

194 recruitment. Similarly, extensive sea ice during the winter would shift distributions of most

195 predators further north, providing more extensive areas for Weddell seals to forage during the

196 Antarctic winter with less competition, thus, we also predicted a positive correlation between

$197 \quad$ SIE $_{\mathrm{w}}$ and probability of recruitment.

198 Open water index (OWI)

199 At the most restricted spatial scale, we developed three seasonal covariates for the $804,000 \mathrm{~km}^{2}$

200 ocean area of the Ross Sea that included the continental shelf and slope. Covariates describing

201 summer (Oct to May) and winter (June-Sept) variation in open water within the Ross Sea were

202 developed using the same passive microwave satellite data employed in constructing sea-ice

203 extent covariates for the Ross Sea sector. Satellite data from alternate days for each seasonal

204 period were processed with all pixels that were classified as open water $(<15 \%$ sea-ice

205 concentration) summed to obtain an estimate of total open water area within the Ross Sea for that

206 day. The daily values were then summed to index the extent and duration of open water for the 
summer $\left(\mathrm{OWI}_{\mathrm{s}}\right)$ and winter $\left(\mathrm{OWI}_{\mathrm{w}}\right)$ periods. No satellite data were available from 3 December

2081987 thru 12 January 1988; therefore, we estimated 1987-88 $\mathrm{OWI}_{\mathrm{s}}$ using the correlation between

209 the $\mathrm{OWI}_{\mathrm{s}}$ derived from complete data sets for the other 19 years in the time series and the $\mathrm{OWI}_{\mathrm{s}}$

210 values obtained with the period of missing data in the 1987-88 data omitted. Similar to SIE , the

211 influence of $\mathrm{OWI}_{\mathrm{s}}$ on probability of recruitment could be positive due to influences on primary

212 production or negative due to increased abundance of competing fish predators. The $\mathrm{OWI}_{\mathrm{w}}$

213 covariate captures variation in the Ross Sea polynya as well as several smaller polynyas along

214 the western Victoria Land coast that are maintained by strong katabatic winds originating on the

215 Antarctic continent (Jacobs and Comiso 1989). While we suspect that the substantial annual

216 variation in these polynyas influences the marine ecosystem and Weddell seals, the paucity of

217 studies focused on the winter ecology of this food web makes it difficult to predict the direction

218 of influence of $\mathrm{OWI}_{\mathrm{w}}$ on measures of reproductive performance of females.

\section{Prevalence of first-year ice (FYI)}

220 Microbial communities that grow in close association with sea ice contribute substantially to

221 annual primary production in the Ross Sea and account for up to $25 \%$ of total annual primary

222 production in ice-covered waters (Arrigo and Thomas 2004). Most of this production occurs on

223 the bottom of first-year sea ice that allows adequate sunlight penetration, with blooms of ice

224 algae and bacteria occurring in spring prior to phytoplankton blooms (Garrison et al. 1986).

225 Hence, we developed a third covariate at the scale of the Ross Sea to index the prevalence of

226 first-year sea ice in spring $\left(\mathrm{FYI}_{\mathrm{s}}\right)$, when sea ice microbial communities would be most

227 productive. We used the passive microwave satellite images processed to quantify open water, as

228 previously described, and identified the date during the summer of year $t-1$ with the maximum

229 open water, then took the amount of open water on that date and subtracted the minimum area of 
230 open water quantified from daily images acquired the subsequent winter. We assumed this

231 quantity indexed the maximum area that could potentially contain first-year ice in spring of year

232 t. Because sea ice microbial communities contribute to annual primary production, and likely

233 have a positive effect on crystal krill that are considered ice-obligate grazers, we predict that

$234 \quad \mathrm{FYI}_{\mathrm{s}}$ would be positively correlated with probability of recruitment.

235 Before employment in modeling, values for each of the environmental covariates were 236 centered to have a mean of 0 and rescaled to have a standard deviation of 1.0. We assessed co-

237 linearity among environmental covariates by calculating pair-wise correlations and variance

238 inflation factors. We also evaluated each time series of environmental covariates for temporal

239 autocorrelation using a wide range of time lags.

240 A priori and exploratory models

241 In order to evaluate the relative contribution of environmental variation during summer and

242 winter seasons and between the periods of maternal provisioning and the initial year of juvenile

243 independence, we constructed four a priori model suites for confrontation with the data: summer-

244 maternal (Mat $)$, winter-maternal $\left(\mathrm{Mat}_{\mathrm{w}}\right)$, summer-juvenile $\left(\mathrm{Juv}_{\mathrm{s}}\right)$, and winter-juvenile $\left(\mathrm{JuV}_{\mathrm{w}}\right)$.

245 For the two seasonal model suites associated with the maternal provisioning period we

246 developed a series of regression models that included combinations of the 5 summer

247 environmental covariates $\left(\mathrm{SOI}_{\mathrm{s}}, \mathrm{ADP}_{\mathrm{s}}, \mathrm{SIE}_{\mathrm{s}}, \mathrm{OWI}_{\mathrm{s}}, \mathrm{FYI}_{\mathrm{s}}\right)$ and another suite using combinations

248 of the 4 winter environmental covariates $\left(\mathrm{SOI}_{\mathrm{w}}, \mathrm{ADP}_{\mathrm{w}}, \mathrm{SIE}_{\mathrm{w}}, \mathrm{OWI}_{\mathrm{w}}\right)$ measured during year $t-1$

249 for the cohort born in year $t$. These models reflect the environmental conditions experienced by

250 the mothers of pups born in that cohort when the mothers were accruing resources to nourish the

251 pup while in utero and during the post-partum nursing period when mothers were fasting. Two

252 additional model suites were similarly constructed for the juvenile-independence period using 
253 the environmental covariates measured during year $t$ that reflected environmental conditions

254 experienced by the pups during their first summer and winter seasons of nutritional

255 independence.

256 To reduce the risk of over-fitting models (Knape and de Valpine 2010), we constrained

257 all a priori models within each suite to include a maximum of only one environmental covariate

258 from each of the 3 spatial scales (climate mode-SOI, ADP; Ross Sea sector-SIE; Ross Sea-OWI,

259 FYI), as well as employing a null intercept-only model. This resulted in a total of 18 models in

260 each of the summer-maternal and summer-juvenile suites and 12 total models in the winter-

261 maternal and winter-juvenile suites. We kept our a priori model lists simple and considered only

262 additive combinations of covariates because knowledge of environmental variation in the Ross

263 Sea and its effects on the marine ecosystem is limited, providing little guidance for developing

264 interaction models, especially given the number of cohorts available for this analysis.

265 Once we completed analysis of a priori models, we evaluated all possible combinations

266 of those environmental covariates from each a priori model suite that were well-supported by the

267 data in an exploratory analysis to further evaluate the relative contribution of environmental

268 variability during the maternal-dependency and juvenile-independence periods. We also

269 evaluated a duplicate set of these exploratory models that included a cohort size covariate as we

270 speculated that cohort size might capture important annual environmental variation not described

271 by our suite of environmental covariates. Not all reproductively mature females produce a pup

272 every year and breeding probabilities (Hadley et al. 2006), as well as temporary emigration rates

273 (Cameron and Siniff 2004), display considerable annual variation that might be associated with

274 variability of food resources available to the females during the year prior to the pupping season, 
275 when conception, implantation, and gestation would occur. Thus we expected a positive

276 correlation between cohort size and recruitment probability.

\section{Data analysis}

278 We modeled the number of female pups from each cohort that recruited into the breeding

279 population by age 10 using a logistic-binomial model (Gelman and Hill 2007), where the number

280 of females that recruited from a given cohort was the number of 'successes' and the size of the

281 cohort was the number of possible successes. We evaluated support for each model within a

282 suite and among suites using an information-theoretic approach and Akaike's Information

283 Criteria (AIC) adjusted for possible overdispersion (QAIC) and sample size (QAIC $_{\mathrm{c}}$. We

284 estimated overdispersion as the smallest dispersion value that was obtained when we evaluated

285 the most complex models in each of our 4 suites, using a logistic model of the counts and a

286 quasibinomial distribution of errors (Gelman and Hill 2007). The most complex models were

287 evaluated with and without cohort size as a covariate. We next evaluated each of the competing

288 models using the logistic-binomial model and adjusted the resulting $\mathrm{AIC}_{\mathrm{c}}$ scores and standard

289 errors using our estimate of over-dispersion. We evaluated the strength of support for each of

290 the competing models both within and among suites. When calculating QAIC $\mathrm{C}_{\mathrm{c}}$ values, we added

2911 to the number of parameters in the model being used, to account for the fact that we had to

292 estimate the amount of over-dispersion. Finally, to provide an approximate measure of the

293 proportion of deviance explained by covariates in the top model, we used analysis of deviance to

294 compute the ratio of differences in quasi-log-likelihood values and to provide a deviance-based

$295 \mathrm{r}^{2}$ metric for covariates of interest (Skalski et al. 1993). The numerator contained the difference

296 in values for the top model and the intercept-only model. The denominator was the difference in

297 values for the global model and the intercept-only model. 


\section{Results}

300 We obtained data from 4,178 female pups born into 20 different cohorts that were each

301 monitored to determine how many of the females recruited to the pup-producing portion of the

302 population within 10 years of birth. The cohorts under investigation here were born during the

303 period 1980-1999 and, with the exception of 1981 when only about $50 \%$ of the pups were tagged

304 due to early ice breakout, contained 165 to 275 female pups each year (mean = 209 females, SD

$305=22)$. The proportion of a cohort that recruited within 10 years averaged $0.20(\mathrm{SD}=0.07)$ and

306 ranged from 0.11 to 0.36 (Table 1). Data on environmental conditions during the maternal-

307 provisioning and juvenile-dependency periods were available for all 20 cohorts, and conditions

308 varied among years (Fig. 1). During the maternal-provisioning period, summer environmental

309 covariate values had pair-wise-correlation values that averaged -0.06 ( $S D=0.36$; range from -

3100.55 to 0.45 ) and variance inflation factors that ranged from 1.33 to 1.82 . During the juvenile-

311 dependency period, summer environmental covariate values had pair-wise-correlation values that

312 averaged $0.02(\mathrm{SD}=0.33$; range from -0.40 to 0.59$)$ and variance inflation factors that ranged

313 from 1.29 to 2.40. Correlations and variance-inflation factors for winter environmental

314 conditions were similar to those for summer covariates. We did not find evidence of important

315 levels of temporal autocorrelation among environmental covariates, as auto-correlation function

316 values at lags of 1 to 13 years were modest: for lag 1 year, values averaged $0.04(\mathrm{SD}=0.25$,

317 range $=-0.40$ to 0.35 ). We estimated over-dispersion in the counts of the number of recruits per

318 cohort as 1.90. Accordingly, we used QAIC ${ }_{c}$ based on an over-dispersion value of 1.90 in model-

319 selection and to inflate variances and confidence intervals. In each suite, there was strong

320 evidence that it was important to consider environmental covariates when modeling the 
321 proportion of the cohort that went on to recruit to the breeding population within 10 years of

322 being born. Accordingly, the intercept-only model received little support within each suite

$323(\Delta \mathrm{QAICc} \geq 14.8$, Table 2$)$.

\section{Summer-maternal covariate suite}

325 The top 2 models both included the Antarctic Dipole $\left(\mathrm{ADP}_{\mathrm{s}}\right)$ and open water index $\left(\mathrm{OWI}_{\mathrm{s}}\right)$, and

326 the $2^{\text {nd }}$ best model also included sea ice extent $\left(\mathrm{SIE}_{\mathrm{s}}\right)$. The $3^{\text {rd }}$ best model contained first year ice

$327\left(\mathrm{FYI}_{\mathrm{s}}\right)$ and $\mathrm{SIE}_{\mathrm{s}}$. Other models in this suite were not well supported by the data in within-suite

328 model comparisons $(\triangle \mathrm{QAICc} \geq 4.3$, Table 2$)$, and Southern Oscillation Index ( $\left.\mathrm{SOI}_{\mathrm{s}}\right)$ did not

329 appear in any well-supported models in the suite $\left(\Delta \mathrm{QAIC}_{\mathrm{c}} \geq 4.64\right)$. In the top model, estimates

330 indicated that a female pup's probability of recruiting was positively related to the ADP

$331\left(\hat{\beta}_{\text {Mat }-A D P}=0.16, \mathrm{SE}=0.06\right.$, Fig. 2$)$ and negatively related to $\mathrm{OWI}_{\mathrm{s}}\left(\hat{\beta}_{\text {Mat }-\mathrm{OWI}}=-0.21, \mathrm{SE}=0.06\right)$

332 during the maternal provisioning period, which was in accordance with our predictions regarding

333 these environmental covariates. Although $\mathrm{SIE}_{\mathrm{s}}$ was in the $2^{\text {nd }}$ - ranked model the estimated

334 coefficient was small and may have been positive or negative $\left(\hat{\beta}_{\text {Mat-SIE }}=0.025, \mathrm{SE}=0.070\right)$.

\section{Summer-juvenile covariate suite}

336 As in the summer-maternal suite, the top model in the summer juvenile covariate suite included

337 the Antarctic Dipole $\left(\mathrm{ADP}_{\mathrm{s}}\right)$ and the open water index $\left(\mathrm{OWI}_{\mathrm{s}}\right)$. The top 6 models all included

$338 \mathrm{ADP}_{\mathrm{s}}$ and up to 1 or 2 other covariates; these were the only models receiving any weight in this

339 suite as all other models had $\Delta \mathrm{QAIC}_{\mathrm{c}} \geq 11.9$ (Table 2). The estimated coefficients for $\mathrm{ADP}_{\mathrm{s}}$

340 were relatively stable among models and supported the prediction that a female pup's probability

341 of recruiting was positively related to $\mathrm{ADP}_{\mathrm{S}}$ (top model: $\hat{\beta}_{J u v-A D P}=0.25, \mathrm{SE}=0.06$, Fig. 2).

342 Estimated coefficients for all other environmental covariates were small and imprecisely

343 estimated. 


\section{Winter-maternal covariate suite}

345 Sea ice extent $\left(\mathrm{SIE}_{\mathrm{w}}\right)$ was in all models within $7.52 \mathrm{QAIC}_{\mathrm{c}}$ units of the top model in the winter-

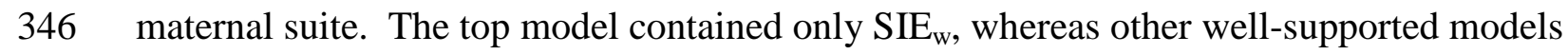

347 included 1 or 2 additional covariates (Table 2). The estimated coefficients for SIE $\mathrm{w}_{\mathrm{w}}$ in this suite

348 of models supported the prediction that a female pup's probability of recruiting was positively

349 related to $\mathrm{SIE}_{\mathrm{w}}$ (top model: $\hat{\beta}_{\text {Mat-SIE }}=0.26, \mathrm{SE}=0.05$, Fig. 2 ). It appears that other top models in

350 the suite gained support from the data because they included SIE $E_{\mathrm{w}}$ the estimated coefficient for

351 SIE $_{\mathrm{w}}$ remained stable and relatively large among well-supported models, while coefficients for

352 other covariate effects were smaller in magnitude and imprecisely estimated. For example, in the

$3532^{\text {nd }}$-best model in the suite, $\hat{\beta}_{\text {Mat }-A D P}=0.09(\mathrm{SE}=0.07)$ whereas $\hat{\beta}_{\text {Mat-SIE }}=0.21(\mathrm{SE}=0.07)$.

\section{Winter-juvenile covariate suite}

355 As was found for the winter-maternal suite, sea ice extent ( $\left.\mathrm{SIE}_{\mathrm{w}}\right)$ was in all models within 14.38

356 QAIC $_{c}$ units of the top model in the winter-juvenile suite (Table 2), and the estimated coefficient

357 associated with $\mathrm{SIE}_{\mathrm{w}}$ was relatively stable and positive (top model: $\hat{\beta}_{J u v-S I E}=0.34, \mathrm{SE}=0.08$,

358 Fig. 2). $\mathrm{SOI}_{\mathrm{w}}$ was in the top two models $\left(\Delta \mathrm{QAIC}_{\mathrm{c}} \leq 0.52\right)$, but, contrary to our prediction, had

359 an estimated coefficient that provided evidence that recruitment probability was negatively

360 related to $\mathrm{SOI}_{\mathrm{w}}\left(\hat{\beta}_{J u v-S O I}=-0.15, \mathrm{SE}=0.07\right)$. The coefficient for $\mathrm{OWI}_{\mathrm{w}}$ was estimated

361 imprecisely enough that it could have been positive or negative.

\section{Comparing across suites}

363 When models from the four suites were compared against one another, the data provided the

364 strongest support for models in the winter-maternal suite. The top six models (cumulative model

365 weight $=0.77$ ) were all from the maternal-winter suite and all were within 2.42 QAIC $_{\mathrm{c}}$ units of

366 the best model, which contained only sea ice extent $\left(\mathrm{SIE}_{\mathrm{w}}\right)$ in the winter-maternal period (Table 
367 3). The top model from the summer-maternal period was the $7^{\text {th }}$-best model $\left(\Delta \mathrm{QAIC} \mathrm{C}_{\mathrm{c}}=3.41\right)$,

368 and the best model from the winter-juvenile period was the next best $\left(\triangle \mathrm{QAIC}_{\mathrm{c}}=3.85\right)$. Models

369 from the summer maternal suite had a cumulative model weight of 0.09, with juvenile winter and

370 summer model suites having cumulative model weights of 0.09 and 0.05 , respectively. Thus, the

371 evidence was strong that a female pup’s eventual recruitment probability was most strongly tied

372 to environmental conditions that the mother experienced during the winter the pup was in utero.

373 The cumulative weight for models containing the covariate for sea ice extent for the winter

374 maternal period, $\mathrm{Mat}_{\mathrm{w}}-\mathrm{SIE}_{\mathrm{w}}$ covariate was 0.77 and was most strongly related to the probability

375 of a female pup recruiting. In contrast, for other winter environmental covariates, cumulative

376 model weights ranged from 0.20 to 0.26 . In the top model, $61 \%$ of the deviance was explained

377 by $\mathrm{Mat}_{\mathrm{w} \_} \mathrm{SIE}_{\mathrm{w}}$, which represents an approximate $\mathrm{r}^{2}$ value for this model. As recommended by

378 one reviewer, we also evaluated additional models that considered the size of the recruited

379 population of females in either year $t$ or year $t-1$ as possible covariates to explore potential

380 density-dependent effects. We evaluated whether the data supported adding population size or

381 the natural logarithm of population size in year $t$ or year $t-1$ to the top a priori model. None of the

3824 models performed as well as the top model, and 95\% CIs for estimated effects of abundance

383 variables overlapped zero in all cases.

384 Exploratory modeling

385 We evaluated all possible combinations of 6 different environmental covariates that were

386 supported by the data in our assessments of the a priori model suites (64 models). These

387 covariates included $\mathrm{Mat}_{\mathrm{w}}-\mathrm{SIE}_{\mathrm{w}}$ (the only variable receiving support from the data in the top

388 model); $\mathrm{Mat}_{\mathrm{s}}-\mathrm{ADP}_{\mathrm{s}}$ and $\mathrm{Mat}_{\mathrm{s}}-\mathrm{OWI}_{\mathrm{s}}$ (the two variables that were in the only summer-maternal

389 model that was within $5 \mathrm{QAIC}_{\mathrm{c}}$ units of the top model in among-suite comparisons); and $\mathrm{Juv}_{\mathrm{w}}{ }^{-}$ 
$\mathrm{OWI}_{\mathrm{w}}, \mathrm{Juv}_{\mathrm{w}}-\mathrm{SIE}_{\mathrm{w}}$, and $\mathrm{Juv}_{\mathrm{w}}-\mathrm{SOI}_{\mathrm{w}}$ (the three variables that were in the only winter-juvenile

391 model that was within 5 QAIC $_{c}$ units of the top model in among-suite comparisons). We also

392 include a duplicate set of models that included cohort size, resulting in a total of 128 exploratory

393 models. This analysis reinforced the results of the a priori analysis with respect to important

394 environmental covariates, but also provided strong support for including cohort size (Fig. 3).

395 The top-ranked exploratory model included cohort size and $\mathrm{Mat}_{\mathrm{w}}-\mathrm{SIE}_{\mathrm{w}}$; the top-ranked a priori

396 model that included only Mat ${ }_{\mathrm{w}}-\mathrm{SIE}_{\mathrm{w}}$ had a $\mathrm{QAIC}_{\mathrm{c}}$ score that was 13.38 units worse. Thirty-eight

397 different models were within $5 \mathrm{QAIC}_{\mathrm{c}}$ units of the top-ranked exploratory model. All of these

398 models included cohort size, and 32 of the 38, including all models within 3 QAIC $_{c}$ units of the

399 top exploratory model, also contained $\mathrm{Mat}_{\mathrm{w}}-\mathrm{SIE}_{\mathrm{w}}$. While other environmental covariates

400 appeared in various combinations in these top-ranked models, cumulative model weights for

401 models pertaining to each of the additional covariates were modest (weights ranged from 0.26 to

402 0.48) and lower than the cumulative weight of 0.90 for models containing Mat ${ }_{\mathrm{w}}-\mathrm{SIE}_{\mathrm{w}}$. Model-

403 specific coefficient estimates for cohort size and $\mathrm{Mat}_{\mathrm{w}}-\mathrm{SIE}_{\mathrm{w}}$ were positive in all cases, and

404 model-averaged estimates had 95\% confidence limits that only included positive values

$405 \quad\left(\hat{\beta}_{\text {cohort size }}=0.004\right.$, unconditional SE $=0.001,95 \%$ confidence limits $=0.002$ to $0.007 ; \hat{\beta}_{W, M-S I E}=$

$4060.165, \mathrm{SE}=0.083,95 \%$ confidence limits $=0.003$ to 0.327 ). Model-averaging produced $95 \%$

407 confidence limits that overlapped zero for coefficients associated with all other covariates

408 considered in exploratory modeling: $\left(\hat{\beta}_{S, M-A D P}=0.01, \mathrm{SE}=0.04,95 \% \mathrm{CI}=-0.06\right.$ to $0.08 ; \hat{\beta}_{S, M-O W I}$

$409=-0.05, \mathrm{SE}=0.07,95 \% \mathrm{CI}=-0.19$ to $0.09 ; \hat{\beta}_{W, J-\text { owI }}=0.09, \mathrm{SE}=0.07,95 \% \mathrm{CI}=-0.04$ to 0.23 ;

$410 \hat{\beta}_{W, J-S I E}=0.09, \mathrm{SE}=0.09,95 \% \mathrm{CI}=-0.09$ to $0.27 ; \hat{\beta}_{W, J-S O I}=-0.08, \mathrm{SE}=0.07,95 \% \mathrm{CI}=-0.22$ to

411 0.06). When we used model averaging to evaluate the effects of changing cohort size and Mat ${ }^{-}$

$412 \operatorname{SIE}_{\mathrm{w}}$, we found that the proportion predicted to recruit for the smallest observed cohort size $(n=$ 
413345 pups) ranged from $0.12(\mathrm{SE}=0.02)$ to $0.21(\mathrm{SE}=0.03)$, as conditions changed from the

414 lowest to the highest levels of $\mathrm{Mat}_{\mathrm{w}}-\mathrm{SIE}_{\mathrm{w}}$. For the maximum cohort size observed $(n=546$

415 pups), predicted proportions ranged from $0.21(\mathrm{SE}=0.04)$ to $0.34(\mathrm{SE}=0.04)$ (Fig. 3).

416

417 Discussion

418 Using data from 20 cohorts of tagged female Weddell seal pups and 30 years of observations of

419 the tagged seals, we documented an approximately 3-fold difference in the proportion of each

420 cohort that returned to the Erebus Bay pupping colonies and produced a pup within the first 10

421 years after birth. The strong support in the data for a priori models correlating this inter-annual

422 variation in recruitment probability and environmental covariates we hypothesized could

423 influence regional ecosystem trophic dynamics provides evidence of a substantial cohort effect

424 and contributes to the growing body of literature demonstrating the effects of environmental

425 conditions during the early stages of life on the subsequent demographic performance of

426 individuals later in life (Forchhammer et al. 2001, Reid et al. 2003, Nevoux et al. 2010).

\section{Proximate mechanism for cohort effect}

428 Recruitment probability is a combination of prebreeding survival probability and age-specific

429 breeding probability. Long-lived mammals tend to have low and variable juvenile survival with

430 much less variable breeding probability (Gaillard et al. 2000). In contrast to many studies of

431 long-lived mammals in both terrestrial and marine systems that have documented relatively low

432 and variable juvenile survival during the maternal dependency period (Gaillard et al. 2000

433 Chambellant et al. 2003), Weddell seal pups have exceptionally high survival to weaning

434 (Proffitt et al. 2010). Estimating annual post-weaning juvenile survival rates in Weddell seals,

435 however, is challenging because, like many other marine birds and mammals, juvenile Weddell 
436 seals temporarily emigrate from natal sites during the lengthy immature period resulting in low 437 detection probabilities (Testa and Siniff 1987). Despite this limitation, several analyses of the 438 mark-resight data from the Erebus Bay population have documented substantial annual variation

439 in juvenile survival estimates for the first several years of independence (Hastings et al. 1999, 440 Cameron and Siniff 2004, Hadley et al. 2006). All studies have consistently estimated mean

441 annual survival as approximately $0.50-0.60$ for the first two years of life, despite difference in 442 analytical methodology and length of the time series used. Although substantial annual variation

443 in age-specific recruitment probability has also been documented in this population (Hadley et al. 444 2006), we suspect that variation in juvenile survival is the predominant contributor to variation in 445 the proportion of a cohort that recruits and plan to initiate an evaluation of cohort-based variation 446 in survival rates to assess this hypothesis.

447 Although we hypothesize that cohort-based variation in juvenile survival is the primary

448 demographic mechanism driving variation in the probability of recruitment by age 10 among

449 Weddell seal cohorts, we found only weak evidence for a correlation between annual

450 environmental conditions during the initial year of juvenile-independence and cohort recruitment

451 probability. Instead, the data strongly support an association between cohort recruitment

452 probability and environmental conditions that the mother experienced during the winter the pup

453 was in utero. These results, therefore, suggest that the primary driver of the observed cohort

454 effects were indirect maternal environmental effects rather than direct environmental effects

455 experienced by the juveniles during their first years of nutritional independence (Maestripieri and 456 Mateo 2009).

457 The most widely recognized maternal effect in mammals is the influence of maternal 458 nutrition on offspring size and growth (Maestripieri and Mateo 2009). This topic has been 
459 investigated in a variety of pinnipeds where females invest a substantial proportion of their body 460 mass in offspring through lactation (Bowen 2009). Weddell seal females invest approximately $46140 \%$ of their post-parturition body mass in their pup during the 30-45 day nursing period, with 462 pups typically tripling in mass from birth to weaning (Wheatley et al. 2006). Several 463 investigations of Weddell seals have demonstrated a strong positive correlation between post464 parturition maternal body mass and pup mass at weaning (Wheatley et al. 2006, Proffitt et al. 465 2007a), similar to studies of other phocid species (Arnbom et al. 1997, Mellish et al. 1999). In 466 addition, Proffitt et al. (2007a,b) found correlations between annual variation in oceanographic 467 and sea ice conditions and maternal post-parturition body mass, as well as annual mean pup 468 weaning mass. Correlations between pup weaning mass and environmental variation 469 experienced by female southern and northern elephant seals have also been reported (Vergani et 470 al. 2001, LeBoeuf and Crocker 2005), with all these investigators concluding that pup weaning 471 mass reflected foraging success of parturient females during the previous year. Given the

472 evidence of a positive relationship between size of progeny and survival during the initial period 473 of nutritional independence in pinnipeds (Hall et al. 2001, Beauplet et al. 2005, McMahon and 474 Burton 2005), as well as ungulates (Albon et al. 1987, Clutton-Brock et al. 1992, Festa-Biachet 475 et al. 1998), we conclude that annual variation in food resources available to pregnant females 476 was likely the driver of variation in recruitment probability among cohorts.

\section{Interpretation of environmental and cohort covariates}

478 While we found consistent support from the evaluation of a priori model suites for a relationship 479 between the probability of recruitment and the Antarctic Dipole in summer and sea-ice extent in 480 winter for both the maternal provisioning and juvenile independence periods, the comparison of 481 models across suites, as well as exploratory analyses, indicated overwhelming support in the data 
482 for the importance of including the winter sea-ice-extent covariate. In addition, there was almost 483 no support in the data for relationships between probability of recruitment and environmental 484 covariates we hypothesized would be linked to primary production (summer indices of sea ice 485 extent, open water, and first year ice). These results are consistent with Ainley et al.’s (2006) 486 hypothesis that the Ross Sea marine ecosystem is strongly structured from the top down. During 487 the open water season, the Ross Sea supports some of the highest densities of top trophic level 488 species found in marine environments (Smith et al. 2007), including Adélie (Pygoscelis adeliae) 489 and emperor (Aptenodytes forsteri) penguins, snow petrels (Pagadroma nivea), minke whales 490 (Balaenoptera acutorostrata), killer whales (Orcinus orca), and Weddell seals. In addition, the 491 large Antarctic toothfish (Dissostichus mawsoni) is a major component of the fish assemblage in 492 the Ross Sea (Eastman 1993) and although population estimates are not available, limited 493 scientific fishing and the recent development of a commercial fishery in the region indicates their 494 numbers are substantial (Dunn and Hanchet 2006). Ainley et al. (2006) suggests that predation 495 by this unusually abundant predator community depletes the mid-trophic level (silverfish and 496 crystal krill), resulting in light grazing pressure on phytoplankton that is inferred from satellite497 based assessments of chlorophyll concentrations (Arrigo and Thomas 2004). Because all of these predators feed heavily on silverfish (Smith et al. 2007), strong

499 exploitative, and potentially interference competition, between Weddell seals in the Ross Sea and 500 other members of the apex predator community is likely during the brief summer open-water 501 period. Most of these predators, however, cannot occupy areas of consolidated sea ice and hence 502 move north out of the Ross Sea in the autumn, as sea ice begins to build and consolidate. Only 503 emperor penguins, Antarctic toothfish, and Weddell seals remain in the Ross Sea during the 504 annual periods of extensive sea ice (Smith et al. 2007). Competition between Weddell seals and 
505 emperor penguins during the prolonged Antarctic winter is largely minimized by temporal and 506 geographic differences in habitat use (Burns and Kooyman 2001), and although Antarctic

507 toothfish may compete with Weddell seals for silverfish, Weddell seals also prey on Antarctic 508 toothfish (Ainley and Siniff 2009). Thus, we suggest that sea-ice extent indirectly influences

509 Weddell seals by moderating the abundance of competing predators in the Ross Sea, and

510 hypothesize that changes in abundance of predators underlie the strong correlation between

511 winter sea-ice extent and probability of recruitment of female pups observed in this study.

512 Because both of the two main mid-trophic species (crystal krill and Antarctic silverfish) that

513 either indirectly or directly influence prey availability for Weddell seals have important life

514 history stages linked to sea ice (Vacchi et al. 2004), it is also possible that variability in winter

515 sea-ice extent influences the abundances of these species, thus contributing to annual variability

516 of prey resources for Weddell seals. These linkages between sea ice and trophic dynamics,

517 combined with demonstrated and predicted changes in the duration and extent of sea ice due to

518 climate change (Cavalieri and Parkinson 2008, Massom and Stammerjohn 2010), suggest

519 significant changes in the Ross Sea ecosystem in the future.

520 While winter sea-ice extent was the dominant environmental covariate receiving support

521 from the data in our analyses, the data also provide modest evidence supporting our hypothesis

522 that the probability of recruitment is positively correlated with the summer Antarctic Dipole

523 covariate. This climate mode is specific to the high latitude southern oceans and has only

524 recently been developed; thus it has seen very limited use in biological studies compared to the

525 commonly used Southern Oscillation Index for the tropical Pacific (Stenseth et al. 2003). A

526 number of investigations of Antarctic and sub-Antarctic marine birds and mammals have

527 demonstrated correlations between SOI and various demographic measures and indices of body 
528 condition (Wilson et al. 2001, McMahon and Burton 2005). Thus, the evidence is strong that

529 this global climate index influences biotic components of marine systems. Despite evidence

530 from previous studies of the influence of SOI on the biology of the Erebus Bay Weddell seals

531 (Testa et al. 1991, Proffitt et al. 2007a, Rotella et al. 2009), the lack of support for Southern

532 Oscillation Index in our analyses suggest that the more regionally-specific Antarctic Dipole may

533 better capture environmental variation in the region of interest in this study (Yuan and Li 2008).

534 Thus, we encourage other ecologists to incorporate the Antarctic Dipole in analyses to further

535 assess its utility as an index of environmental variation in the high southern latitudes.

$536 \quad$ Although our results clearly indicate that sea-ice extent and the Antarctic Dipole index

537 reflect aspects of environmental variation that are important to Weddell seals, such indices are

538 likely to be imperfect measures of the multitude of conditions experienced by organisms that

539 either directly or indirectly influence the seals' complex life cycle and the adequacy of available

540 resources to meet physiological and life-history demands. We evaluated cohort size as a

541 potential covariate in exploratory analyses because we hypothesized that the number of seals that

542 produce pups in a given year may be a more integrative index of annual variation in

543 environmental conditions. The strong support in the data for this covariate affirms this

544 hypothesis. There is considerable evidence from studies of a variety of taxa that annual breeding

545 probability and fecundity are state-dependent, i.e., are influenced by an individual's condition

546 (McNamara and Houston 1996). We interpret the existence of skip-breeders in the Erebus Bay

547 Weddell seal population as evidence of this phenotypic plasticity in breeding probability (Testa

548 and Siniff 1987). We hypothesize that the mechanism for this plasticity may involve the

549 approximately 6-8-week period from conception to implantation. If most of the accumulation of

550 body reserves necessary to support pregnancy and the subsequent lactation period are accrued 
551 during the austral summer then the rate of mass gain, as dictated by prey availability, may

552 provide a signal that dictates whether the blastocyst implants or not. In years of lower prey

553 availability a larger proportion of the breeding females may fail to implant, hence prey

554 availability during the previous summer may dictate the size of the pup cohort born the following

555 spring. This interpretation is reinforced by an integrated mark-recapture analysis using 30 years

556 of data that found a positive correlation among survival and breeding probabilities across years,

557 and also provides further support for the influence of annual variation in environmental

558 conditions on numerous aspects of Weddell seal demographic performance (Rotella et al. In

559 review).

560 Cohort effects and individual phenotypic variation

561 In conclusion, we have demonstrated a cohort effect in our Weddell seal study population that

562 contributes to the growing body of studies in a variety of taxa, occupying diverse ecological

563 settings, and that have quantified the existence and magnitude of cohort effects in populations

564 (Lindström 1999). Similar to many other studies involving long-lived organisms, we argue that

565 the mechanism responsible for the measured cohort effect in this Weddell seal population is a

566 result of environmental variation influencing maternal investment in progeny, which in turn

567 contributes to an individual's phenotype and ultimate fitness. Thus, cohort effects introduce

568 individual phenotypic variation into this, as well as other populations.

569 The consequences of cohort effects on the dynamics of a population, however, are not

570 easily understood, because there are a number of other processes that also contribute to

571 individual phenotypic variation. Clearly in all sexually reproducing organisms both maternal

572 and paternal genetic effects contribute to individual variation. In organisms with extended

573 parental care, there is also the potential for maternal (and in some species paternal) behavioral 
574 effects (Maestripieri and Mateo 2009). In this respect, the Weddell seal is relatively unique

575 among phocids, because of its long period of maternal care, which can last 30-45 days (Wheatley

576 et al. 2006), with extensive mother-pup interactions both on the ice surface and in the water

577 (Testa et al. 1989, Sato et al. 2003). All three types of maternal effects (genetic, environmental,

578 and behavioral) represent latent or static traits that influence an individual's phenotype and

579 contribute to heterogeneity among individuals within a population. However, additional

580 variability in an individual's phenotype is introduced by dynamic traits that change over an

581 individual's life, such as age, reproductive experience, social status, and body mass (Bergeron et

582 al. 2010). Some of these processes that contribute to individual phenotypic variation are

583 aggregated across groups of individuals, such as the cohort effect demonstrated in this study, and

584 others, such as genetic effects, introduce random phenotypic variation among individuals

585 (Wilson and Nussey 2010).

586 The relative contribution of each of these sources of individual phenotypic variation,

587 interacting with the life history characteristics of the organism, dictate the degree to which

588 individual variation stabilizes or destabilizes the dynamics of a population (Lindström and

589 Kokko 2002, Beckerman 2003). Advances in our understanding of these complex interactions in

590 long-lived organisms will require long-term longitudinal studies of tractable species where

591 individuals can be studied from birth to death and aspects of population dynamics, as well as

592 individual demographic performance and attributes, can be carefully quantified (Clutton-Brock

593 and Sheldon 2010). An ongoing challenge for these research programs will be quantifying

594 individual phenotypic variation, identifying the relative contribution of the numerous underlying

595 mechanisms leading to this variation, and evaluating the consequences of this variation on

596 individual fitness and population dynamics. 
598 Acknowledgments - This work was supported by the National Science Foundation OPP-

5990635739 grant to R. A. Garrott, J. J. Rotella, and D. B. Siniff. Prior NSF grants to R. A. Garrott,

600 J. J. Rotella, D. B. Siniff, and J. W. Testa supported the collection of data used in this paper.

601 Support for C. L. Parkinson was provided by NASA’s Cryosphere Program; and Nick

602 DiGirolamo of Science Systems and Applications, Inc., assisted in the processing of the satellite-

603 based sea ice data. X. Yuan and C. Li of Lamont-Doherty Earth Observatory of Columbia

604 University shared knowledge of the El Niño/Southern Oscillation (ENSO)-sea ice teleconnection

605 and provided a time series of Antarctic Dipole data for use in this study. We are grateful to the

606 many individuals who have worked on projects associated with the Erebus Bay Weddell seal

607 population since the 1960s. Animal handling protocols were approved by Montana State

608 University’s Animal Care and Use Committee (Protocol \#41-05).

609 


\section{References}

611 Ainley, D. G. et al. 2006. Competition among penguins and cetaceans reveals trophic cascades in the western Ross Sea, Antarctica. - Ecology 87: 2080-2093.

613 Ainley, D. G. and Siniff, D. B. 2009. The importance of Antarctic toothfish as prey of Weddell seals in the Ross Sea. - Antarctic Sc. 21: 317-327.

615 Albon, S. D. et al. 1987. Early development and population dynamics in red deer. II. Density616 independent effects and cohort variation. - J. Anim. Ecol. 56: 69-81.

617 Anderson, A.E. et al. 1974. Growth and morphometry of the carcass, selected bones, organs, and 618 glands of mule deer. Wild. Monogr. no. 39.

619 Arnbom, T. et al. 1997. Factors affecting maternal expenditure in southern elephant seals during 620 lactation. - Ecology 78: 471-83.

621 Arrigo, K. R. and Thomas, D. N. 2004. Large scale importance of sea ice biology in the Southern Ocean. - Antarctic Sc. 16: 471-486.

623 Arrigo, K. R. and Van Dijken, G. L. 2004. Annual changes in sea-ice, chlorophyll $a$, and primary production in the Ross Sea, Antarctica. - Deep-Sea Res. II 51: 117-138.

625 Arrigo, K. R. and Van Dijken, G. L. 2007. Interannual variation in air-sea $\mathrm{CO}_{2}$ flux in the Ross Sea, Antarctica: a model analysis. - J. Geophys. Res. 112 :C03020, doi:10.1029/2006JC003492.

628 Beauplet, G. et al. 2005. Interannual variation in the post-weaning and juvenile survival of subantarctic fur seals: influence of pup sex, growth rate and oceanographic conditions. -

$630 \quad$ J. Anim. Ecol. 74: 1160-1172.

631 Beckerman, A. P. et al. 2003. Talkin’ 'bout my generation: environmental variability and cohort effects. - Am. Nat. 162: 754-767. 
633 Bergeron, P. et al. 2010. Individual quality: tautology or biological reality? - J. Anim. Ecol., doi: 10.1111/j.1365-2656.2010.01770.x

Bowen, W. D. 2009. Maternal effects on offspring size and development in pinnipeds. - In: Maestripieri, D. and Mateo, J. M. (eds.), Maternal effects in mammals. University of

Burns, J. M. and Kooyman, G. L. 2001. Habitat use by Weddell seals and emperor penguins foraging in the Ross Sea, Antarctica. - Am. Zool. 41: 90-98.

Cameron, M. F. and Siniff, D. B. 2004. Age-specific survival, abundance, and immigration rates of a Weddell seal (Leptonychotes weddellii) population in McMurdo Sound, Antarctica. -

643 Cavalieri, D. J. et al. 1991. Aircraft active and passive microwave validation of sea ice concentration from the DMSP SSM/I. - J. Geophys. Res. 96: 21,989-22,008.

Cavalieri, D. J. and Parkinson, C. L. 2008. Antarctic sea ice variability and trends, 1979-2006. J. Geophys. Res. 113, C07004, doi:10.1029/2007JC004564.

Chambellant, M. et al. 2003. Long-term evaluation of pup growth and preweaning survival rates in subantarctic fur seals, Arctocephalus tropicalis, on Amsterdam Island. - Can. J. Zool. 81:1222-1232.

654

Clutton-Brock, T. H. et al. 1992. Early development and population fluctuations in Soay Sheep. - J. Anim. Ecol. 61: 381-96.

Clutton-Brock, T. and Seldon, B. C. 2010. Individuals and populations: the role of long-term, individual-based studies of animals in ecology and evolutionary biology. - Trends Ecol. Evol. 25: 562-573. 
655 Croxall, J. P. et al. 2002. Environmental change and Antarctic seabird populations. - Science $656 \quad 297: 1510-1514$.

657 Dunn, A. and Hanchet, S. M. 2006. Assessment models for Antarctic toothfish (Dissostichus 658 mawsoni) in the Ross Sea including data from the 2005-06 season. CCAMLR document WG-FSA-06/60.

660 Eastman, J. T. 1993. Antarctic fish biology: evolution in a unique environment. - Academic 661 Press.

662 Festa-Bianchet, M. et al. 1998. Mass- and density-dependent reproductive success and reproductive costs in a capital breeder. - Am. Nat. 152: 367-379.

664 Forchhammer, M. C. et al. 2001. Climate and population density induce long-term cohort variation in a northern ungulate. - J. Anim. Ecol. 70: 721-729.

Gaillard, J. -M. et al. 2000. Temporal variation in fitness components and population dynamics of large herbivores. - Annu. Rev. Ecol. Syst. 31: 367-393.

668 Garrison, D. L. et al. 1986. Sea ice microbial communities in Antarctica. - BioScience 36: 243250.

670 Gelman, A. and Hill, J. 2007. Data analysis using regression and multilevel/hierarchical models. - Cambridge University Press.

672 Hadley, G. L. et al. 2006. Variation in probability of first reproduction of Weddell seals. - J. Anim. Ecol. 75: 1058-1070.

674 Hadley, G. L. et al. 2007a. Evaluation of reproductive costs for Weddell seals in Erebus Bay, $675 \quad$ Antarctica. - J. Anim. Ecol. 76: 448-458.

676 Hadley, G.L., J.J. Rotella, and R.A. Garrott. 2007b. Influence of maternal characteristics on 677 survival and recruitment probabilities of Weddell seals. Oikos 116:601-613. 
Hall, A. et al. 2001. Factors affecting first-year survival in grey seals and their implications for life history. - J. Anim. Ecol. 70: 138-149.

Halpern, B. S. et al. 2008. A global map of human impact on marine ecosystems. - Science 319: 948-951.

Hastings, K.K., J.W. Testa, and E.A. Rexstad. 1999. Interannual variation in survival of juvenile Weddell seals (Leptonychotes weddellii) from McMurdo Sound, Antarctica: effects of cohort, sex and age. - J. Zoology (London) 248: 307-323.

Ichii, T. et al. 1998. Interannual changes in body fat condition index of minke whales in the Antarctic. - Mar. Ecol. Prog. Ser. 175: 1-12.

Jacobs, S. and Comiso, J. 1989. Sea ice and oceanic processes on the Ross Sea continental shelf. - J. Geophys. Res. 94(C12): 18195-18211.

Jönnsson, K. I. 1997. Capital and income breeding as alternative tactics of resource use in reproduction. - Oikos 78: 57-66.

Knape, J. and de Valpine, P. 2010. Effects of weather and climate on the dynamics of animal population time series. - Proc. R. Soc. B. doi: 10.1098/rspb.2010.1333.

LeBoeuf, B. J. and Crocker, D. E. 2005. Ocean climate and seal condition. - BMC Biology 3: $1743-49$.

Lindström, J. 1999. Early development and fitness in birds and mammals. - Trends Ecol. Evol. 14: 343-348.

Lindström, J. and Kokko, H. 2002. Cohort effects and population dynamics. - Ecol. Lett. 5: 338344.

Massom, R. A. and Stammerjohn, S. E. 2010. Antarctic sea ice change and variability - Physical and ecological implications. - Polar Sci. 4: 149-186. 
701 Maestripieri, D. and J.M. Mateo. 2009. The role of maternal effects in mammalian evolution and adaptation. - In: Maestripieri, D. and Mateo, J. M. (eds.), Maternal effects in mammals. Univ. Chicago Press, pp. 1-10.

704 McNamara, M. and Houston, A. J. 1996. State-dependent life histories. - Nature 380: 215-221.

705 McMahon, C. R. and Burton, H. R. 2005. Climate change and seal survival: evidence for environmentally mediated changes in elephant seal, Mirounga leonine, pup survival. -

Mellish, J. A. E. et al. 1999. Variation in milk production and lactation performance in grey seals and consequences for pup growth and weaning characteristics. - Physiol. Biochem. Zool.

711 Nevoux, M. et al. 2010. Long- and short-term influence of environment on recruitment in a species with highly delayed maturity. - Oecologia 162: 383-392.

713 Parkinson, C. L. 2004. Southern Ocean sea ice and its wider linkages: Insights revealed from 714 models and observations. - Antarctic Science 16: 387-400.

715 Parker, K.L., et al. 1993. Seasonal patterns in body mass, body composition, and water transfer rates of free-ranging and captive black-tailed deer (Odocoileus hemionus sitkensis) in

718 Parkinson, C. L. and Cavalieri, D. J. 2008. Arctic sea ice variability and trends, 1979-2006. - J. Geophys. Res. 113, C07003, doi:10.1029/2007JC004558.

720 Proffitt, K. M. et al. 2007a. Environmental and senescent related variations in Weddell seal body

721 mass: implications for age-specific reproductive performance. - Oikos 116: 1683-1690.

722 Proffitt, K, M. et al. 2007b. Exploring linkages between abiotic oceanographic processes and a 723 top-trophic predator in an Antarctic Ecosystem. - Ecosystems 10: 119-126. 
724 Proffitt, K. M. et al. 2010. Effects of pup age, maternal age, and birth date on pre-weaning 725 survival rates of Weddell seals in Erebus Bay, Antarctica. - Oikos 119: 1255-1264.

726 Reid, J. M. et al. 2003. Environmental variability, life-history covariation and cohort effects in 727 the red-billed chough Pyrrhocorax pyrrhocorax. - J. Anim. Ecol. 72: 36-46.

728 Rotella, J. J. et al. 2009. An evaluation of density-dependent and density-independent influences on population growth rates in Weddell seals. - Ecology 90: 975-984.

730 Rotella, J. J. et al. In review. Evaluating the demographic buffering hypothesis with vital rates estimated for Weddell seals from 30 years of mark-recapture data. - J. Anim. Ecol.

732 Sato, K. et al. 2003. Synchronous shallow dives by Weddell seal mother-pup pairs during lactation. - Mar. Mamm. Sci. 19: 384-395.

734 Schulz, T. M. and Bowen, W. D. 2004. Pinniped lactation strategies: evaluation of data on 735 maternal and offspring life history traits. - Mar. Mamm. Sci. 20: 86-114.

736 Skalski, J. R., Hoffman, A., and Smith, S. G. 1993. Testing the significance of individual- and 737 cohort-level covariates in animal survival studies. Pages 9-28 In J.-D. Lebreton and P.

740 Smith Jr., W. O. et al. 2007. Marine ecosystems: the Ross Sea. - Philos. Trans. R. Soc., B362: $95-111$.

742 Stenseth, N. C. et al. 2003. Studying climate effects on ecology through the use of climate indices: the North Atlantic Oscillation, El Niño Southern Oscillation and beyond. - Proc.

745 Stephens, P. A. et al. 2009. Capital breeding and income breeding: their meaning, measurement, $746 \quad$ and worth. - Ecology 90: 2057-2067. 
Stirling, I. 1969. Ecology of the Weddell seal in McMurdo Sound, Antarctica. - Ecology 50: 573-586.

Testa, J. W. et al. 1989. Diving behavior and maternal investment in Weddell seals (Leptonychotes weddellii). - Mar. Mamm. Sci. 5: 399-405.

Testa, J. W. et al. 1991. Temporal variability in Antarctic marine ecosystems: Periodic fluctuations in the phocid seals. - Can. J. Fish. Aquat. Sci. 48: 631-639.

Testa, J. W. and Siniff, D. B. 1987. Population dynamics of Weddell Seals (Leptonychotes weddellii) in McMurdo Sound, Antarctica. - Ecol. Monogr. 57: 149-165.

Turchin, P. 2003. Complex population dynamics: a theoretical/empirical synthesis. - Princeton Univ. Press.

Vacchi, M. et al. 2004. Early life stages in the life cycle of Antarctic silverfish, Pleuragramma antarcticum, in Terra Nova Bay, Ross Sea. - Antarct. Sci. 16: 299-305.

Vaughan, D. G. et al. 2001. Climate change: devil in the detail. - Science 293: 1777-1779.

Vaughan, D. G. et al. 2003. Recent rapid regional climate warming on the Antarctic Peninsula. Climatic Change 60: 243-274.

Walsh, J. E. 2008. Climate of the Arctic marine environment. - Ecol. Appl. 18: S3-S22.

Wheatley, K. E. et al. 2006. Influence of maternal mass and condition on energy transfer in Weddell seals. - J. Anim. Ecol. 75: 724-733.

Wheatley, K. E. et al. 2008. Feast or famine: evidence for mixed capital-income breeding strategies in Weddell seals. - Oecologia 155: 11-20.

Wilson, P. R. et al. 2001. Adélie penguin population change in the pacific sector of Antarctica: relation to sea-ice extent and the Antarctic Circumpolar Current. - Mar. Ecol. Prog. Ser. 213: 301-309. 
770 Wilson, A. J., and Nussey, D. H. 2010. What is individual quality? An evolutionary perspective.

$771 \quad$ - Trends Ecol. Evol. 25: 207-214.

772 Yuan, X. 2004. ENSO-related impacts on Antarctic sea ice: A synthesis of phenomenon and 773 mechanisms. - Antarctic Science 16: 415-425.

774 Yuan, X. and Li, C. 2008, Climate modes in southern high latitudes and their impacts on

775 Antarctic sea ice. - J. Geophys. Res., 113, C06S91, doi:10.1029/2006JC004067. 
Table 1. The number of Weddell seal pups born and tagged at traditional colony sites within Erebus Bay, Antarctica, over 20 consecutive years, and the proportion of the female pups in each cohort that returned to the colonies and recruited (produced a pup) within 10 years of birth. In all years except 1981, all pups in each cohort were tagged at birth. (Ignoring the anomalous year, 1981, the mean values for the remaining years are: 419 animals, 209 females, and 0.20 proportion of females recruited.)

\begin{tabular}{cccc}
\hline Cohort & $\begin{array}{c}\text { No. } \\
\text { animals }\end{array}$ & $\begin{array}{c}\text { No. } \\
\text { females }\end{array}$ & $\begin{array}{c}\text { Propor. } \\
\text { females } \\
\text { recruited }\end{array}$ \\
\hline 1980 & 422 & 207 & 0.106 \\
1981 & $202 *$ & $108 *$ & 0.157 \\
1982 & 385 & 201 & 0.134 \\
1983 & 391 & 213 & 0.192 \\
1984 & 390 & 203 & 0.128 \\
1985 & 410 & 201 & 0.174 \\
1986 & 413 & 196 & 0.214 \\
1987 & 410 & 206 & 0.165 \\
1988 & 423 & 201 & 0.149 \\
1989 & 384 & 206 & 0.194 \\
1990 & 440 & 208 & 0.216 \\
1991 & 424 & 210 & 0.214 \\
1992 & 345 & 165 & 0.182 \\
1993 & 450 & 228 & 0.171 \\
1994 & 378 & 182 & 0.165 \\
1995 & 385 & 193 & 0.176 \\
1996 & 379 & 203 & 0.241 \\
1997 & 546 & 275 & 0.280 \\
1998 & 490 & 237 & 0.333 \\
1999 & 499 & 227 & 0.361 \\
\hline
\end{tabular}

*Only 50\% pups tagged due to early ice breakout 
Table 2. Model selection results comparing a priori models used to examine the effects of environmental covariates on variation in probability of recruitment within 10 years of birth for 20 cohorts of female Weddell seal pups born from 1980 through 1999 in Erebus Bay, Antarctica.

A priori models were partitioned into four suites, representing summer and winter conditions experienced by the pups' mothers prior to parturition (Maternal) and summer and winter conditions experienced by pups during their first year of nutritional independence following weaning (Juvenile). Environmental covariates are Southern Oscillation Index (SOI), Antarctic Dipole (ADP), Sea-Ice Extent (SIE), Open Water Index (OWI), and First-Year Ice Index (FYI), with subscripts deliniating summer (s) and winter seasons (s).

\begin{tabular}{|c|c|c|c|c|}
\hline \multirow[b]{2}{*}{ Model structure } & \multirow[b]{2}{*}{ K } & \multicolumn{3}{|c|}{ Within suite } \\
\hline & & $\Delta \mathrm{QAIC}_{\mathrm{c}}$ & $\mathrm{wi}_{\mathrm{C}}$ & cum. wt \\
\hline \multicolumn{5}{|l|}{ Summer - Maternal } \\
\hline $\mathrm{ADP}_{\mathrm{s}}+\mathrm{OWI}_{\mathrm{s}}$ & 4 & 0.00 & 0.44 & 0.44 \\
\hline $\mathrm{ADP}_{\mathrm{s}}+\mathrm{OWI}_{\mathrm{s}}+\mathrm{SIE}_{\mathrm{s}}$ & 5 & 1.88 & 0.17 & 0.61 \\
\hline $\mathrm{FYI}_{\mathrm{S}}+\mathrm{SIE}_{\mathrm{s}}$ & 4 & 2.89 & 0.10 & 0.71 \\
\hline $\mathrm{FYI}_{\mathrm{s}}$ & 3 & 4.31 & 0.05 & 0.76 \\
\hline $\mathrm{ADP}_{\mathrm{s}}+\mathrm{FYI}_{\mathrm{s}}+\mathrm{SIE}_{\mathrm{s}}$ & 5 & 4.59 & 0.04 & 0.81 \\
\hline $\mathrm{FYI}_{\mathrm{s}}+\mathrm{SIE}_{\mathrm{s}}+\mathrm{SOI}_{\mathrm{s}}$ & 5 & 4.64 & 0.04 & 0.85 \\
\hline Intercept-only & 2 & 17.01 & 0.00 & \\
\hline \multicolumn{5}{|l|}{ Summer - Juvenile } \\
\hline $\mathrm{ADP}_{\mathrm{s}}+\mathrm{OWI}_{\mathrm{s}}$ & 4 & 0.00 & 0.26 & 0.26 \\
\hline $\mathrm{ADP}_{\mathrm{s}}$ & 3 & 0.18 & 0.24 & 0.51 \\
\hline $\mathrm{ADP}_{\mathrm{s}}+\mathrm{SIE}_{\mathrm{s}}$ & 4 & 0.76 & 0.18 & 0.69 \\
\hline $\mathrm{ADP}_{\mathrm{s}}+\mathrm{OWI}_{\mathrm{s}}+\mathrm{SIE}_{\mathrm{s}}$ & 5 & 1.82 & 0.11 & 0.79 \\
\hline $\mathrm{ADP}_{\mathrm{s}}+\mathrm{FYI}_{\mathrm{s}}+\mathrm{SIE}_{\mathrm{s}}$ & 5 & 1.87 & 0.10 & 0.90 \\
\hline $\mathrm{ADP}_{\mathrm{s}}+\mathrm{FYI}_{\mathrm{s}}$ & 4 & 1.91 & 0.10 & 1.00 \\
\hline Intercept-only & 2 & 14.77 & 0.00 & \\
\hline \multicolumn{5}{|l|}{ Winter - Maternal } \\
\hline $\mathrm{SIE}_{\mathrm{w}}$ & 3 & 0.00 & 0.27 & 0.27 \\
\hline $\mathrm{SIE}_{\mathrm{w}}+\mathrm{ADP}_{\mathrm{w}}$ & 4 & 0.60 & 0.20 & 0.48 \\
\hline $\mathrm{SIE}_{\mathrm{w}}+\mathrm{SOI}_{\mathrm{w}}$ & 4 & 0.90 & 0.17 & 0.65 \\
\hline $\mathrm{SIE}_{\mathrm{w}}+\mathrm{OWI}_{\mathrm{w}}$ & 4 & 0.98 & 0.17 & 0.82 \\
\hline $\mathrm{SIE}_{\mathrm{w}}+\mathrm{ADP}_{\mathrm{w}}+\mathrm{OWI}_{\mathrm{w}}$ & 5 & 2.27 & 0.09 & 0.91 \\
\hline $\mathrm{SIE}_{\mathrm{w}}+\mathrm{SOI}_{\mathrm{w}}+\mathrm{OWI}_{\mathrm{w}}$ & 5 & 2.42 & 0.08 & 0.99 \\
\hline Intercept-only & 2 & 20.42 & 0.00 & \\
\hline
\end{tabular}




\begin{tabular}{lcccc}
$\mathrm{SIE}_{\mathrm{w}}+\mathrm{SOI}_{\mathrm{w}}+\mathrm{OWI}_{\mathrm{w}}$ & 5 & 0.00 & 0.34 & 0.34 \\
$\mathrm{SIE}_{\mathrm{w}}+\mathrm{SOI}_{\mathrm{w}}$ & 4 & 0.52 & 0.26 & 0.61 \\
$\mathrm{SIE}_{\mathrm{w}}$ & 3 & 1.38 & 0.17 & 0.78 \\
$\mathrm{SIE}_{\mathrm{w}}+\mathrm{OWI}_{\mathrm{w}}$ & 4 & 2.44 & 0.10 & 0.88 \\
$\mathrm{SIE}_{\mathrm{w}}+\mathrm{ADP}_{\mathrm{w}}$ & 4 & 2.91 & 0.08 & 0.96 \\
$\mathrm{SIE}_{\mathrm{w}}+\mathrm{OWI}_{\mathrm{w}}+\mathrm{ADP}_{\mathrm{w}}$ & 5 & 4.36 & 0.04 & 1.00 \\
$\mathrm{Intercept} \mathrm{Only}$ & 2 & 16.57 & 0.00 & \\
\hline
\end{tabular}


Table 3. Model selection results of among-suite comparisons that contrasted the most-supported models from each of four a priori model suites used to examine the effects of environmental covariates on variation in probability of recruitment within 10 years of birth of 20 cohorts of female Weddell seal pups born from 1980 through 1999 in Erebus Bay, Antarctica (see Table 2). A priori models were partitioned into four suites representing summer and winter conditions experienced by the pups' mothers prior to parturition (Mat ${ }_{s}$ and $\mathrm{Mat}_{\mathrm{w}}$ ) and summer and winter conditions experienced by pups during their first year of nutritional independence following weaning $\left(\operatorname{Juv}_{\mathrm{s}}\right.$ and $\left.\mathrm{Juv}_{\mathrm{w}}\right)$. Environmental covariates are Southern Oscillation Index (SOI), Antarctic Dipole (ADP), Sea-Ice Extent (SIE), Open Water Index (OWI), and First-Year Ice Index (FYI), with subscripts deliniating summer (s) and winter seasons (w).

\begin{tabular}{lccccc}
\hline Model structure & $\mathrm{K}$ & QAIC $_{\mathrm{c}}$ & $\Delta$ QAIC $_{\mathrm{c}}$ & $\mathrm{W}_{\text {ic }}$ & cum. $_{\text {ic }}$ \\
\hline Mat $_{\mathrm{w}}-\mathrm{SIE}_{\mathrm{w}}$ & 3 & 95.61 & 0.00 & 0.21 & 0.21 \\
$\mathrm{Mat}_{\mathrm{w}}-\mathrm{SIE}_{\mathrm{w}}+\mathrm{ADP}_{\mathrm{w}}$ & 4 & 96.21 & 0.60 & 0.16 & 0.37 \\
$\mathrm{Mat}_{\mathrm{w}}-\mathrm{SIE}_{\mathrm{w}}+\mathrm{SOI}_{\mathrm{w}}$ & 4 & 96.51 & 0.90 & 0.14 & 0.50 \\
$\mathrm{Mat}_{\mathrm{w}}-\mathrm{SIE}_{\mathrm{w}}+\mathrm{OWI}_{\mathrm{w}}$ & 4 & 96.59 & 0.98 & 0.13 & 0.64 \\
$\mathrm{Mat}_{\mathrm{w}}-\mathrm{SIE}_{\mathrm{w}}+\mathrm{ADP}_{\mathrm{w}}+\mathrm{OWI}_{\mathrm{w}}$ & 5 & 97.88 & 2.27 & 0.07 & 0.70 \\
$\mathrm{Mat}_{\mathrm{w}}-\mathrm{SIE}_{\mathrm{w}}+\mathrm{SOI}_{\mathrm{w}}+\mathrm{OWI}_{\mathrm{w}}$ & 5 & 98.03 & 2.42 & 0.06 & 0.77 \\
$\mathrm{Mat}_{\mathrm{s}}-\mathrm{ADP}_{\mathrm{s}}+\mathrm{OWI}_{\mathrm{s}}$ & 4 & 99.03 & 3.41 & 0.04 & 0.81 \\
$\mathrm{Juv}_{\mathrm{w}}-\mathrm{SIE}_{\mathrm{w}}+\mathrm{SOI}_{\mathrm{w}}+\mathrm{OWI}_{\mathrm{w}}$ & 5 & 99.47 & 3.85 & 0.03 & 0.84 \\
$\mathrm{Juv}_{\mathrm{w}}-\mathrm{SIE}_{\mathrm{w}}-\mathrm{SOI}_{\mathrm{w}}$ & 4 & 99.98 & 4.37 & 0.02 & 0.86 \\
\hline
\end{tabular}


Figure 1. The environmental covariate conditions in each year from 1979 through 1999 that were considered in a priori models of the probability of recruitment of female Weddell seals for 20 cohorts (1980-1999). Black lines depict winter conditions and gray lines depict summer conditions for each covariate. All covariate values are expressed as standardized values (mean $=0$, sd $=1)$ with standardization performed separately for each covariate and season. Environmental covariates are Southern Oscillation Index (SOI), Antarctic Dipole (ADP), Sea-Ice Extent (SIE), Open Water Index (OWI), and First-Year Ice Index (FYI). 
Figure 1

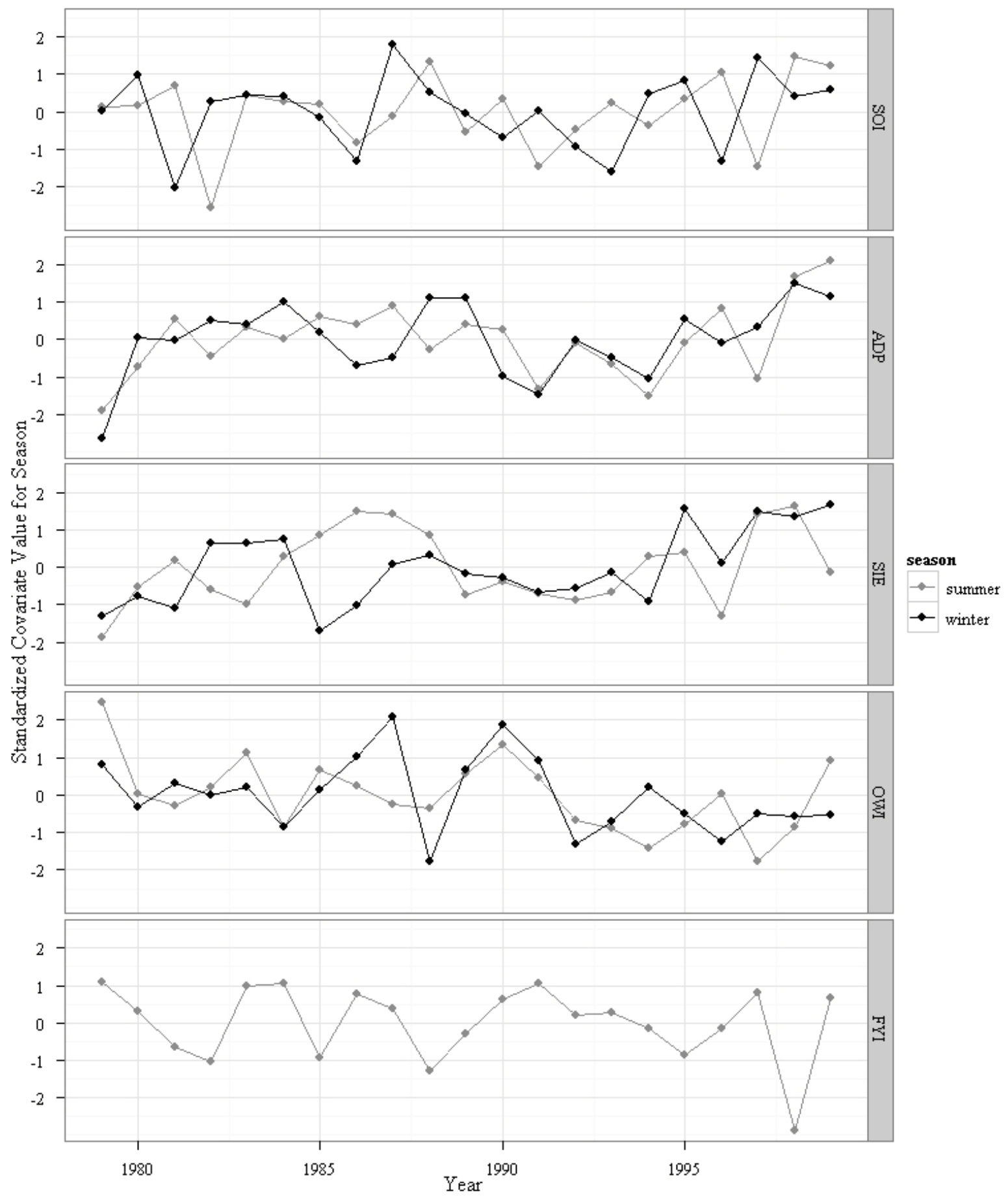


Figure 2. Correlations between the observed proportion of female Weddell seal pups $( \pm 1$ SE, with SE adjusted for overdispersion) from 20 cohorts (1980-1999) that recruited into the population within 10 years of birth versus the most important environmental covariate in each a priori model suite. Environmental covariates during the period of maternal pregnancy (Maternal) and the initial year of juvenile independence (Juvenile) were evaluated. Covariates were standardized, with the Antarctic Dipole climate mode during the summer $\left(\mathrm{ADP}_{\mathrm{s}}\right)$ and winter sea-ice extent in the Ross Sea sector $\left(\mathrm{SIE}_{\mathrm{w}}\right)$ most strongly correlated with recruitment probability (see Table 2). 
Figure 2
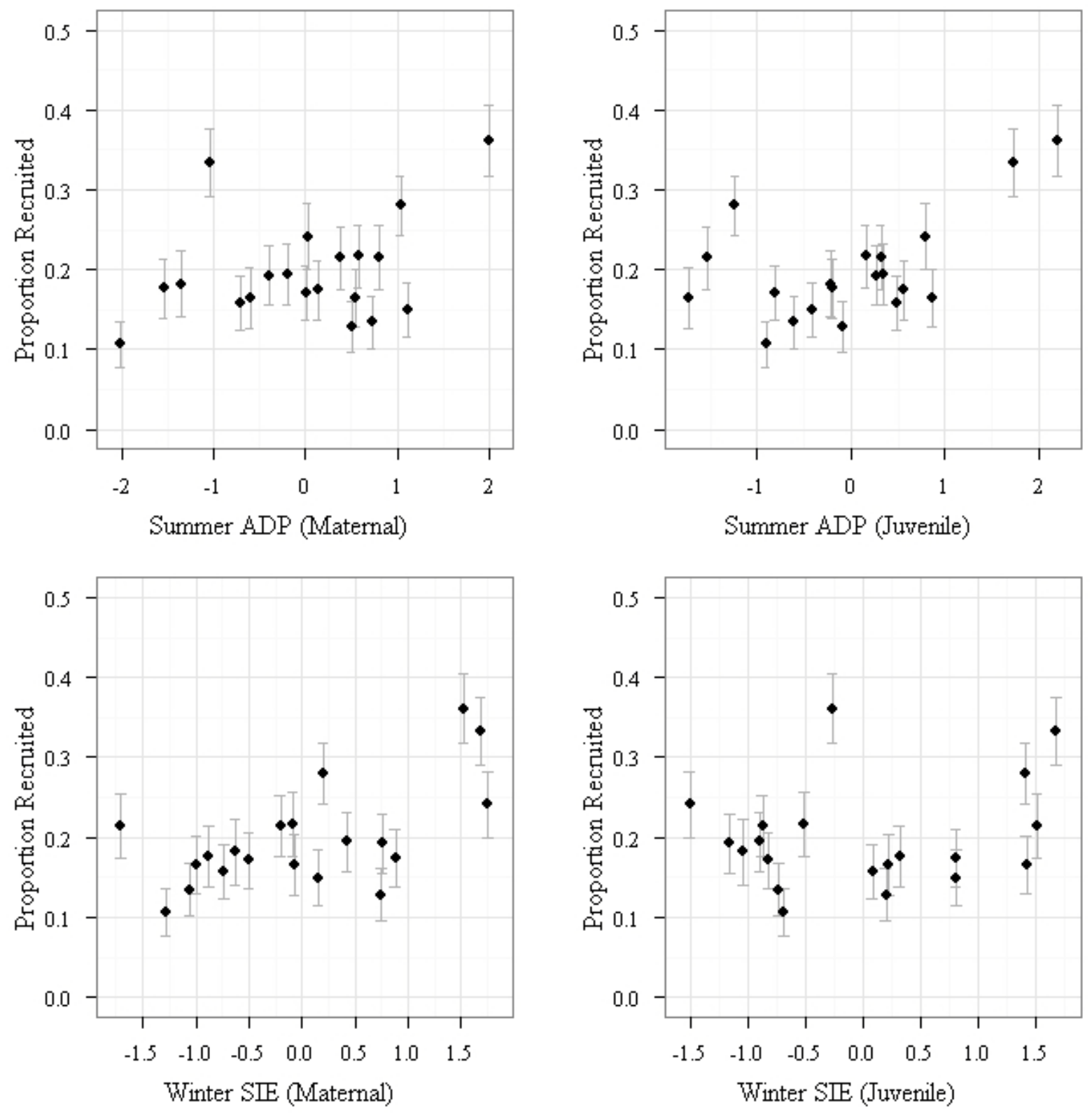
Figure 3. Proportion of female pups recruiting within 10 years of being born presented as (a) model-averaged predictions across all a priori models as functions of cohort size and sea-ice extent during the winter $\left(\mathrm{SIE}_{\mathrm{w}}\right.$ ) before the pup was born (the upper solid line is for the largest cohort size observed [ $n=546$ pups], and the lower solid line is for the smallest cohort size observed [ $n=345$ pups]; dotted lines represent 95\% confidence limits for predictions), and (b) annual proportions based on observed data (filled circles) and predictions from the bestsupported a priori model (stars), best-supported exploratory model (open circles), and the null model (open squares). 
Figure 3
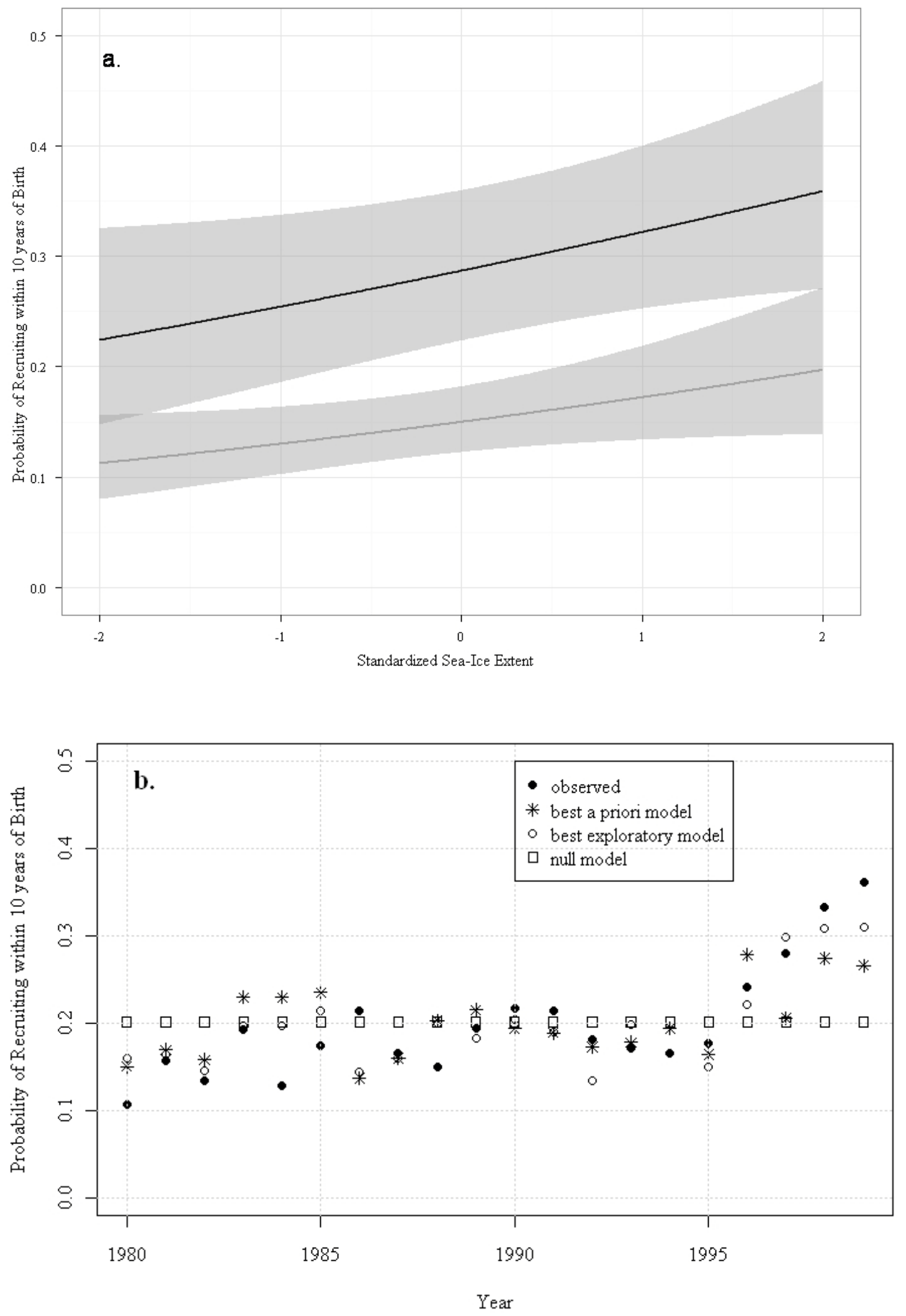